\title{
COLONIZATION AND STRATEGIC STRATIFICATION OF BUTTERFLY Pachliopta aristolochiae (LEPIDOPTERA: PAPILIONIDAE) AND ITS RELATIONSHIP WITH THE HOST PLANT Aristolochia indica (PIPERALES: ARISTOLOCHIACEAE)
}

\author{
Alam, S., M. A. Bashar, U. Aich, S. Akand and S. Rahman \\ Environmental Biology and Biodiversity Laboratory (EBBL), Department of Zoology, University of \\ Dhaka, Dhaka-1000, Bangladesh
}

\begin{abstract}
Colonization experiment for the butterfly Pachliopta aristolochiae (Fabricius, 1775) (Lepidoptera: Papilionidae) was carried out in the Zoological Garden, Curzon Hall, University of Dhaka and Bhawal national park, Gazipur from 2010 to 2011, and butterfly host-plants and nectar-plants were identified for this purpose. The field observations and identification confirmed that the host plant species Aristolochia indica is a creeper plant. A. indica was cultivated for the butterfly oviposition behaviour and to continue developmental stages. The oviposition behaviour of gravid female, hatching, feeding and moulting behaviour of the four larval instars, and pupation behaviour of $A$. indica were recorded. Both laboratory and field observations revealed that while there was availability of food, $1^{\text {st }}$ and $2^{\text {nd }}$ instar larvae preferred tender leaves, whereas the $3^{\text {rd }}$ and $4^{\text {th }}$ instar larvae fed both on young and mature leaves. However, mature larvae were also observed to feed on the stems, flower and fruits of the host-plant in absence of suitable succulent leaves. The feeding time was recorded for each larval instars and it was relatively low for $1^{\text {st }}$ and $2^{\text {nd }}$ instar larvae, remarkably higher in $3^{\text {rd }}$ instar larvae and highest in the case of ultimate and penultimate larval instars. The egg, larval and pupal mortalities were counted during the study period. Their survivability rate was $80 \%$ or more. This result was found to stand good for a successful colonization process of the butterfly P. aristolochiae.
\end{abstract}

Key Words: Behaviour, egg-laying, feeding potential, larva, pupation.

\section{INTRODUCTION}

The red-bodied swallowtail butterfly Pachliopta aristolochiae is known as the Common Rose, belonging to the family Papilionidae of the order Lepidoptera (Basher 2014, Alam et al. 2014). The butterfly is abundant across South and South East Asia (Wynter-Blyth 1957, Aich et al. 2016). Field examination reveals that this butterfly has a sub marginal row of red lunular markings and a discal row of white spots on upper side of hind wings (Barua and Slowik 2007). The hind wings also bear robust club-shaped black tails. The wingspan is $80-100 \mathrm{~mm}$ (Haribal 1992, Alam et al. 2014). The egg hatches to larva in a characteristic pattern. There are four successive larval instars before the butterfly goes for pupation (Bashar 2015). The female of another swallowtail species, Papilio polytes (Common Mormon) as well as of the Rose Windmill (Atrophaneur alatreillei) mimic the Common Rose (Barua and Slowik 2007). The adult butterflies prefer the flowers of Lantana camara, Clerodendrum infortunatum, Rouwolfia serpentine, Cosmos bipinnatus, Vincarosea, Duranto repens, Citrus medica, Hibiscus rosasinensis, Moringa pterygosperma and Bauhinia variegate for nectaring while the larva feeds on the creeper Aristolochia tagala (Barua and Slowik 2007). This swallowtail butterfly is rarely seen on mud puddling although it prefers sunshine (Haribal 1992). The larval food plant Aristolochia indica belongs to the family Aristolochiaceae, it is a poisonous vine in nature having pharmacological properties (Che et al. 1984). As the butterfly is host specific on the host plants, it is popularly known as poison-eater (Bashar 2015).

To colonize the $P$. aristolochiae in a suitable ecosystem it is necessary to study the life cycle of this butterfly along with the study of host plant's phenology; and its association with the shelter plants (Bashar 2015). Culture of this species in an ecosystem enhances restocking their population 
withstanding their slow and continuous depletion. Therefore, it serves as a measure for the conservation of biodiversity as a whole (Gay et al. 1992).

However, to establish an ex-situ conservation in an ecosystem one needs a complete knowledge of its biology and autecology including its life history, voltinism, seasonality and habitat conditions. Data on larval performance in respect to the food consumption, utilization and growth, and information on adult's nectar sources are necessary for the effective conservation measures of this species (Ramana et al. 2013). Hence, the present study was undertaken to investigate thoroughly the life cycle of the $P$. aristolochiae butterfly along with a study on its oviposition strategy, larval feeding potential on the different leaf maturity stages, pupation strategy and also the possible causes of egg damage, larval and pupal mortality.

\section{MATERIAL AND METHODS}

All experiments (including field observation and laboratory rearing) were conducted in the Zoological Garden, Curzon hall campus, University of Dhaka and Butterfly Park, Bhawal National Park, Gazipur from January 2010 to February 2011. The identification of the associated host plants (viz. nectar, shelter and resting plants) identification was made following Kunte (2006), Aravind (2005), Cheng et al. (2000), Lederhous et al. (1992), Wiklund and Ahrberg (1978). Two hedges of A. indica were selected for the assistance of this experiment. The butterfly activities in the fields were recorded following Young (2009). Data were collected on egg-laying strategy from August, 2010 till the last of November, 2010 at 24 hour interval. Laboratory rearing was conducted in a plastic rearing box which was kept inside a steel framed net case $(32 \times 18 \times 18 \mathrm{~cm})$. Larval feeding was observed providing them with host plant leaves. These were kept moist by watering twice daily to prevent drying out. The data on the larval behaviour, egg laying behaviour, pupating characteristics were recorded following Hern et al. (1996), Mamun et al. (2008), Obara et al. (2008), Bergman et al. (2007), Pola and Gracia-Paris (2005), Scott (1974) and Ilse (1956). The recorded data were subjected to critical analysis statistically for further investigation.

\section{RESULTS AND DISCUSSION}

Like other butterflies, $P$. aristolochiae had four stages in the life cycle, viz. egg, larva, pupa and adult. The eggs were round in shape, flattened at the bottom and were brick red at the top, the remaining portion was dark orange in colour. A gravid female generally laid 8-10 eggs at a time scatteredly on different leaves of the host plant in field conditions. She did it within a time span of five minutes. The incubation period was $3 \pm 1$ days.

The duration of egg hatch was 25-30 minutes. The freshly emerged first instar larvae were transparent pale red with faint blackish markings on the body and covered with minute pale yellowish fleshy spines. The larvae started feeding on egg case about 10 minutes after hatching and its colour changed to pale brown after 45 minutes. At this stage body length and width could be up to $5 \mathrm{~mm}$ and $1.5 \mathrm{~mm}$, respectively with duration of \pm 2 days. The $2^{\text {nd }}$ instar larval body was brownish black bearing 12 pairs of fleshy spines on both dorsal and lateral sides. The first 5 pairs of dorsal spines were brownish red colour, the 6th pair creamy white and the last 6 pairs of abdominal spines were again brownish red colour. The first 5 pairs of lateral fleshy spines were, however, brownish black colour. In the 6th segment, the paired dorsal and lateral spines were joined on each side by a white line. The 2nd instars larval duration was \pm 3 days, having the body length and width up to $9 \mathrm{~mm}$ and $3 \mathrm{~mm}$, respectively. The $3^{\text {rd }}$ instar larva was velvety black and covered with 12 pairs of fleshy spines. The dorsal spines were brick red while the lateral spines were black with red tips. The 6th pair of dorsal and lateral spines was reddish white and joined on both sides by a pair of reddish white lateral lines. Also in the 6th segment, a 
white line measuring $1 \mathrm{~mm}$ in thickness joined the brick red dorsal spines on the upper side. The larvae grew up to a length of $2.8 \mathrm{~cm}$ and a breadth of 3-4 mm having larval duration of \pm 4 days. The $4^{\text {th }}$ instar larvae had a dark velvety black body and the fleshy spines were crimson red colour at the upper portion and black at the basal half. The 6th segment dorsal and lateral spines were creamy white colour, joined both dorsally and laterally by thick white lines. Just after moulting, the 6th segment fleshy spines were pale orange colour, which gradually faded with a mild orange tinge at their free apical tips. The first three anterior segments had an additional pair of pale red fleshy spines. All the spines were becoming more prominent with increasing thickness. The larvae attained a length of $4 \mathrm{~cm}$ and breadth of $8 \mathrm{~mm}$ and their average larval duration was \pm 6 days.

After 13-16 days of growth and reaching a maximum length of around 40-48 $\mathrm{mm}$ in the final instar larvae, the body of the caterpillar gradually shrinked in the pre-pupal stage. The caterpillar ceased eating and wandered around for a pupation site. At the chosen site, the caterpillar readied itself for the pupation by spinning a silk griddle and a silk pad. Pupation took place after one day of the pre-pupal stage. The pupa was light brown colour with a mixture of white, orange and dark brown patterned markings on the dorsal side. The ventral side was light brown with faint white stripes. The anterior end of the chrysalis was produced into a frontally flattened broad projection, which further had a pair of flattened flaps on either lateral side. The 2 nd pair of dorso-ventrally flattened flaps was present in the mid-anterior region. The pupal size was $(25 \times 15) \mathrm{mm}$ and the pupal duration was $12 \pm 1$ days.

The adults were observed to emerge from the pupa by splitting open the case vertically on the dorsal side. The time taken for emergence was recorded 1-2 hours. The common rose completed 7-8 generations in a year. The first generation emerged in March and the last generation was completed in the last week of November.

Very distinctive-three categories of bio-cyclic states were found to derive from the present investigation's results while analyzing the activities in different stages of life cycle of the butterfly. With the host plant's phenology, the butterfly was found to pass through the following activities: a. egg laying strategy; b. larval food habitat and feeding pattern; and c. pupating and characteristic resting periodicity.

\section{Egg laying Strategy}

The egg laying behaviour of $P$. aristolochiae was held at daylight. During the host plant searching, the butterfly was seen to vibrate its wings rapidly and repeatedly visiting the host plants and trying to probe the leaves for ascertaining their suitability for egg-laying like the tender nature of the leaves and availability of shade. After repeatedly flying around the host plant for 5-8 minutes, a female laid eggs.

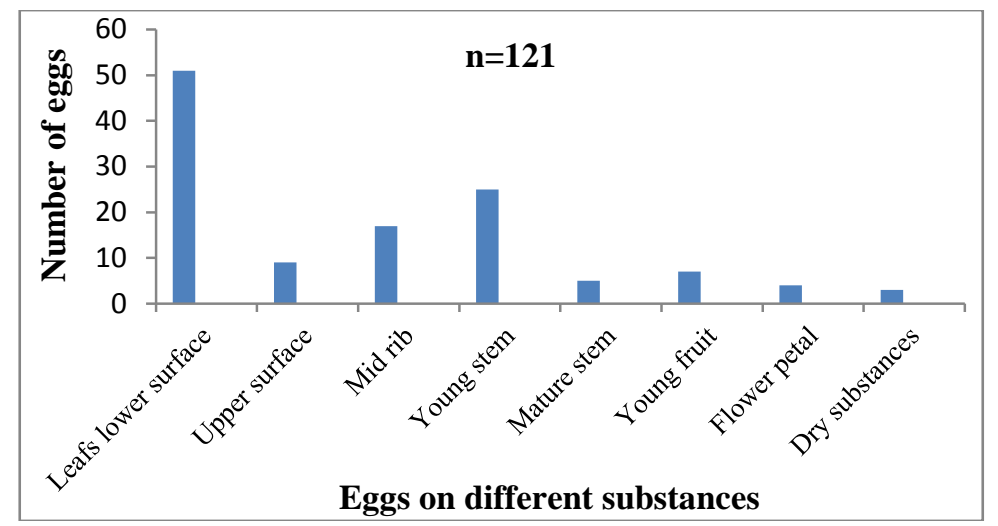

Fig. 1. Number of P. aristolochiae eggs laid on different substances ( $\mathrm{n}=$ the number of eggs). 


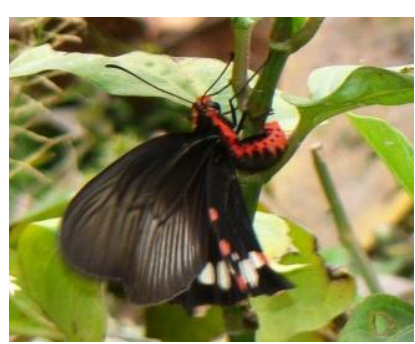

a

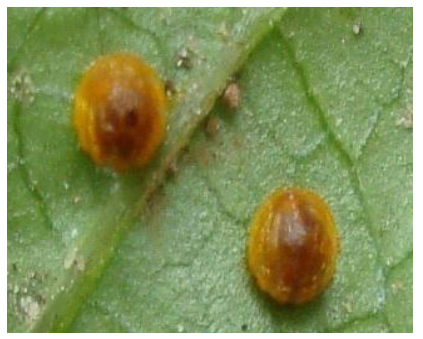

e

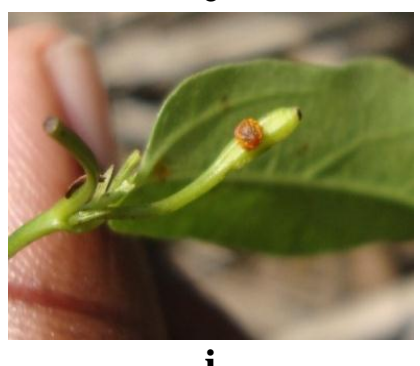

i

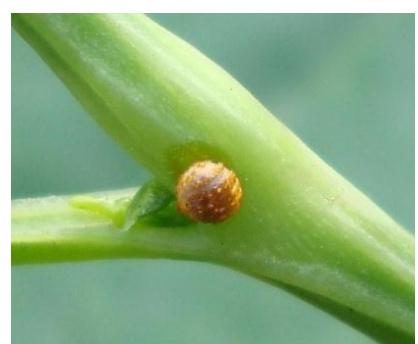

b

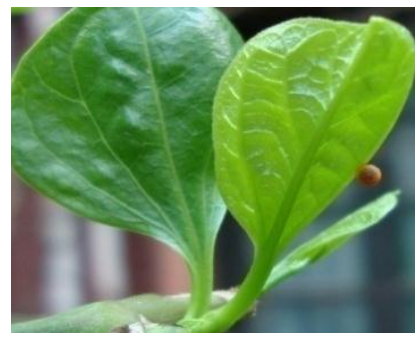

f

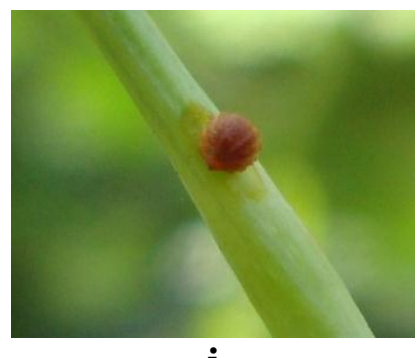

j

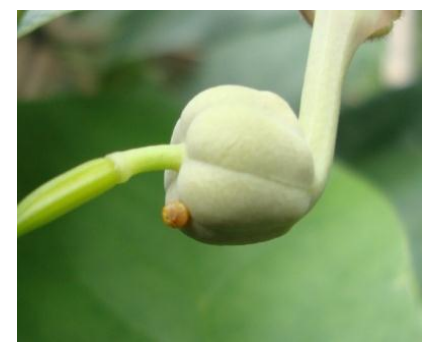

c

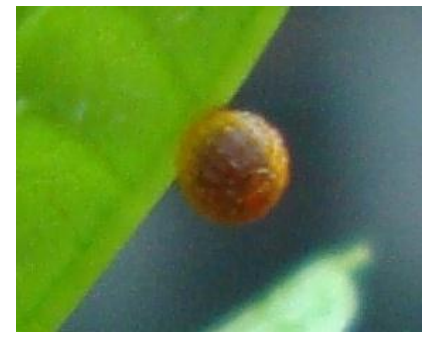

g

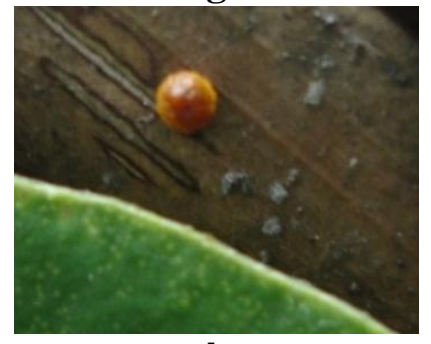

$\mathbf{k}$

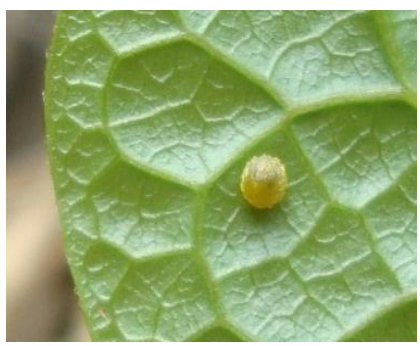

d

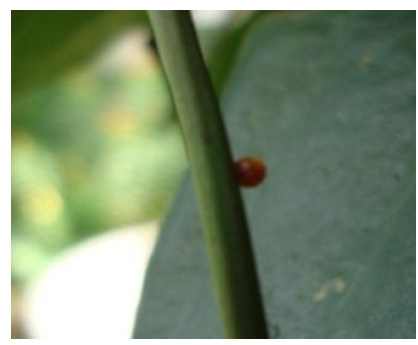

h

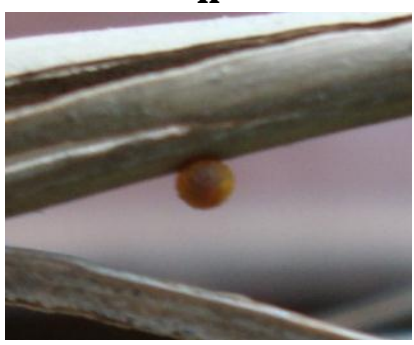

l

Fig. 2. Spatial distribution of egg deposition and the host plant's phonological stages in P. aristolochiae (a-l). a. Egg laying adult; Eggs on b. axial bud, c. flower petal, d. and e. leaf lamina, f. leaf margin, g. leaf mid rib, h. mature stem, i. young fruit, $\mathbf{j}$. young stem, $\mathbf{k}$. dry coconut leaf, l. bamboo stick.

During the study period it was observed that 121 eggs were laid on different parts of host plants and other substances (Fig. 1.). The female laid eggs on the tender leaves, under surface of young leaves, mid rib of leaves, leaf stalk, flower petals, young fruits, on young and mature stem, node, leaf margin, axial bud etc. (Fig. 2.). Sometimes, a large number of eggs became matured and the female took heavy burden to retain the eggs. In this situation, if the female could not find a suitable place on the host plant, it deposited the eggs on even dry plant-substances (Figs. 2. k, 1).

\section{Larval Food Habitat and Feeding Pattern}

The first instar larvae slowly emerged by splitting open the egg cage at apical tip. The time recorded for hatching was 25-30 minutes. The freshly emerged larvae started feeding on the yellow coloured empty egg cage only after about 10 minutes of emergence. They defoliated the very tender leaves by making small irregular shaped holes (Fig. 3.a, Fig. 5.). The feeding time was 1-2 minutes followed by a resting period of 60-80 minutes. The larvae were sluggish and took rest on the other side of the leaves. The second instar larvae also preferred to feed on the tender leaves and defoliated along the side of leaf margin (Fig. 3.b, Fig. 5.). The feeding time was 2-3 minutes followed by a resting period of 60-80 minutes. While feeding, the larvae defoliated the leaves from the lower side itself and therefore remained least exposed to predators (Fig. 3.b). 


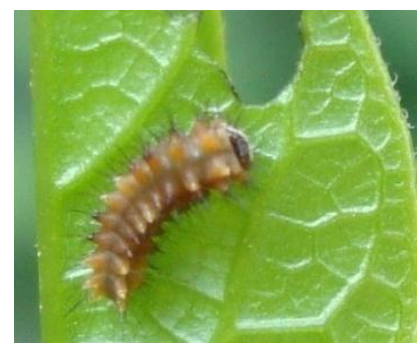

$\mathbf{a}$

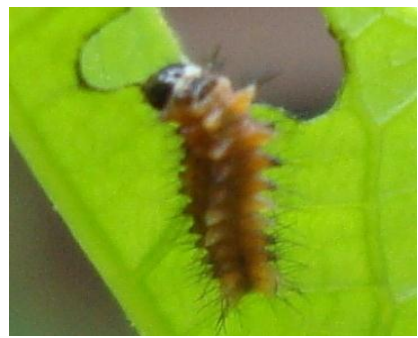

b

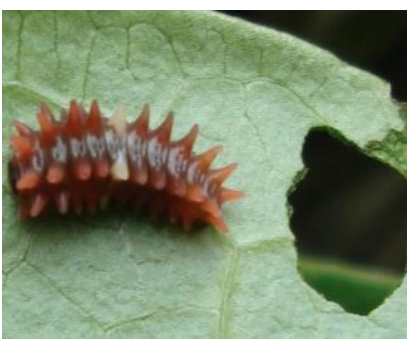

c

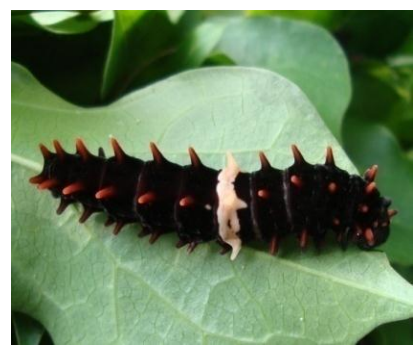

d

Fig. 3. Larval feeding of $P$. aristolochiae; a. First instar larva feeding on a tender leaf, b. Second instar larva feeding on leaf lamina, c. Third instar larva feeding on a mature leaf, d. Fourth instar larva feeding on mature leaf.

The mature third instar larvae were voracious feeder, which defoliated tender, young and mature leaves (Fig. 3.c, Fig. 5.). In the absence of suitable leaves, they were also observed to feed on the tender shoots of the host-plant. The feeding time was recorded 10-15 minutes followed by a resting period of 30-40 minutes.

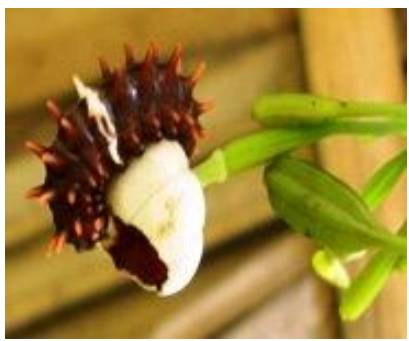

$\mathbf{a}$

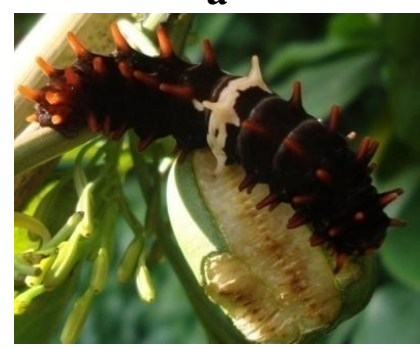

e

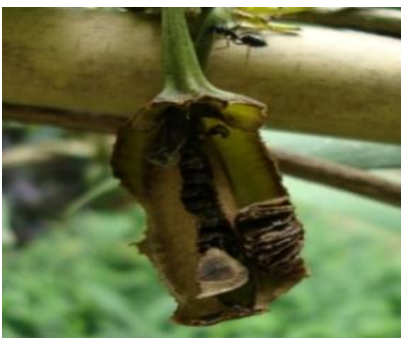

i

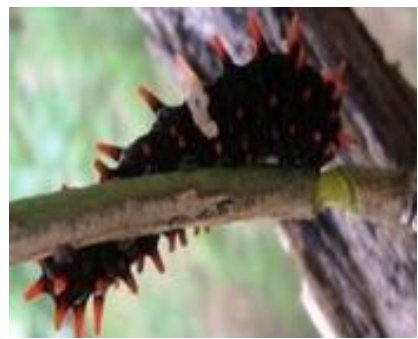

b

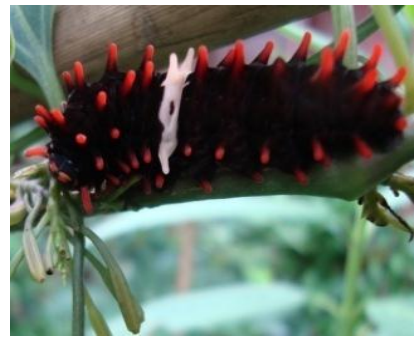

f

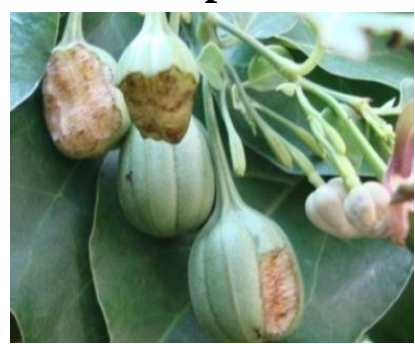

j

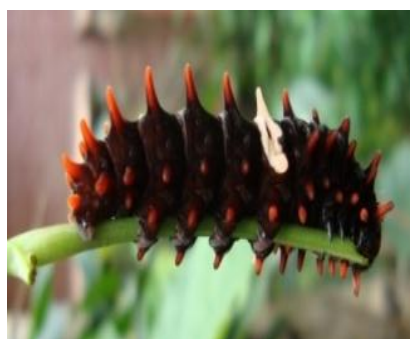

c

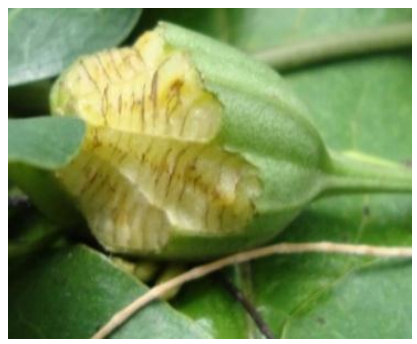

g

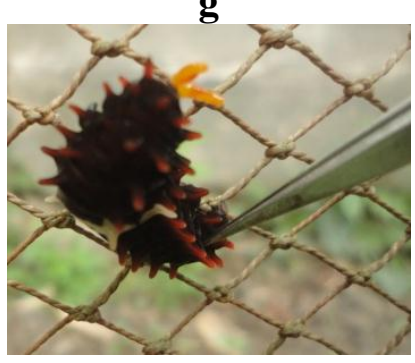

k

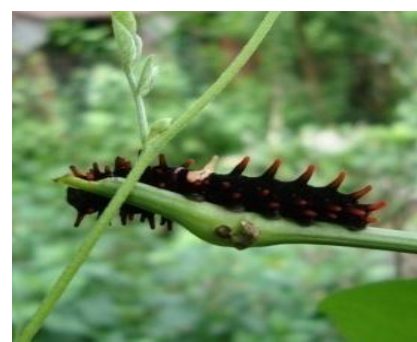

d

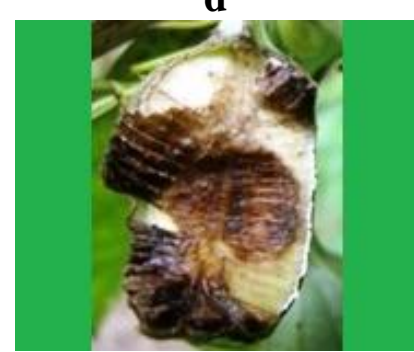

h

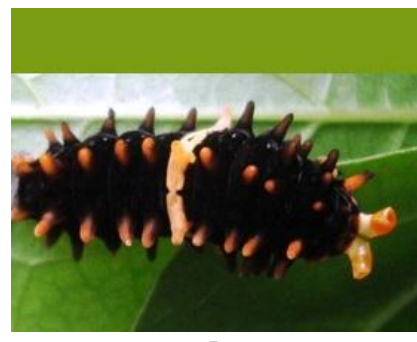

I

Fig. 4. Fourth instar larvae of $P$. aristolochiae feeding on different body parts of host plants (a-f); a. petals, b. mature stem bark, c. young stem, d. mature stem, e. mature fruit, f. axillary bud; causeing fruit damage (g, h, i, j); ejected osmateria when disturbed (k-l)

The robust fourth instar larvae were also found as most voracious feeders, which preferred to defoliate the mature leaves (Fig. 5.) and in the absence of suitable leaves they were found to consume the young, mature shoots, fruits, the androecium and gynoecium of the host plants (Fig. 4. a-j). The 
feeding time was recorded 25-30 minutes followed by a resting period of 50-70 minutes. When disturbed, they ejected out a pair of orange-coloured osmateria and quickly moved away to a different site (Fig. 4. k-1).

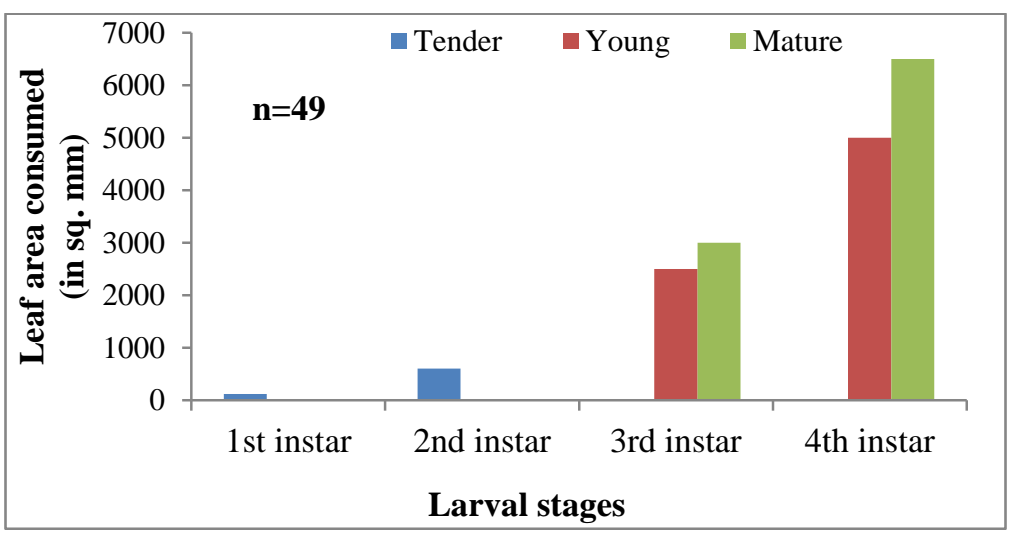

Fig. 5. Leaf area consumption preference by four larval instars of $P$. aristolochiae $(\mathrm{n}=$ the number of larva).

\section{Moulting}

The larvae stopped their feeding prior to moulting. They selected the underside of mature leaves and completed the process of skin changing within 5-8 minutes (Fig. 6.). After moulting, larvae were seen feeding on the skin cast.

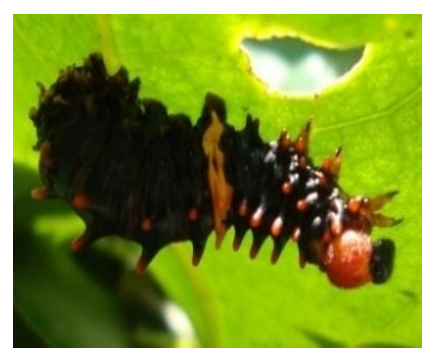

$\mathbf{a}$

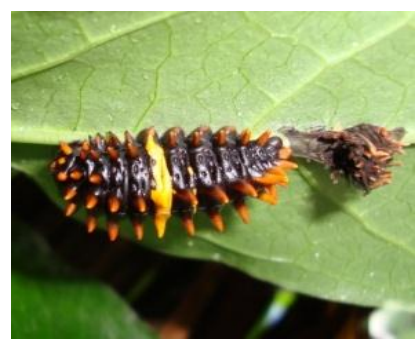

b

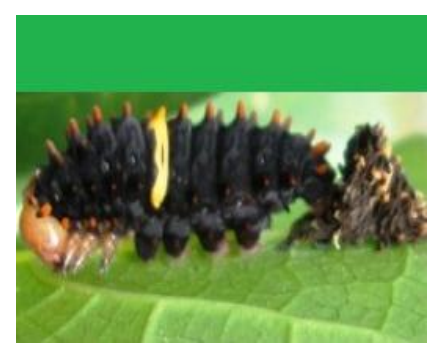

c

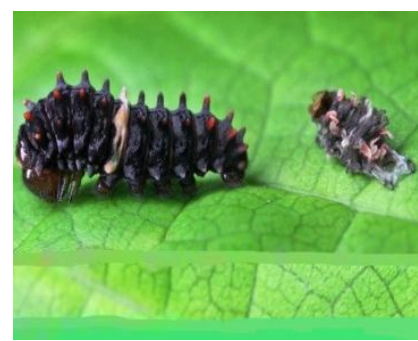

d

Fig. 6. Different stages of moulting in the larvae ecdysing to fourth instar $(\mathbf{a}, \mathbf{b}, \mathbf{c}, \mathbf{d})$.

Pupating and Characteristic Resting Periodicity

About 6-8 hours prior to pupation, the $4^{\text {th }}$ instar larvae stopped feeding and within next two hours were observed to eject out all the waste matter in the form of dark greenish-black, semi-solid mass. They were reduced in body size and vigorously moved about in search of a suitable pupation site and always selected the mature stem of the host plant. In absence of sufficient mature stem and bushy stem the larvae go for pupation on shade plant, shade substances, neighbouring bushy plant and also go even longer distance. Due to the lack of enough mature stem larvae go for pupation on dry shade substances, bamboo sticks, iron rod, net, neighbouring plants Cissus quadrangularis (Harjora), Capsicum frutescens (Chili), Hisbiscusrosa-sinensis (Jaba) and on other hedge plants. They first remained static for 15-20 minutes and then slowly fixed the posterior tip of the body to the stem and at the same time secreted a sticky black thread like girdle or chimaster from the mouth, which surrounded the interior part of the body from side to side. This took another 15 minutes. The body now slowly acquired an arch shape. They remain in this stage for the next 24-48 hours. Following was the completion of changes in the pupating larvae into a light brown coloured chrysalis stage (Fig. 7.(a-d)). The entire process of pupation was completed within 14-15 hours. After data collection, it was observed that pupation (\%) on dry shade 
substances was more than mature stem, neighbouring plants and others as shown in Fig. 7(e). They emerged after more or less 12 days.

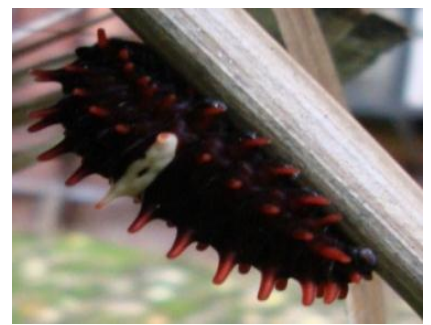

$\mathbf{a}$

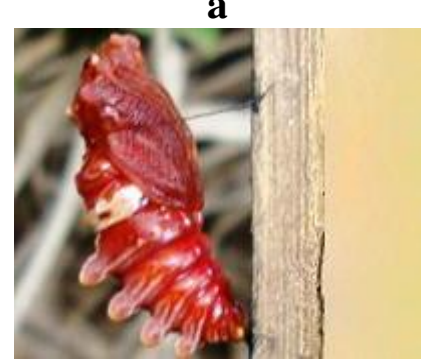

c

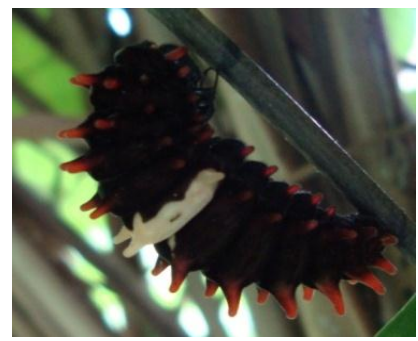

b

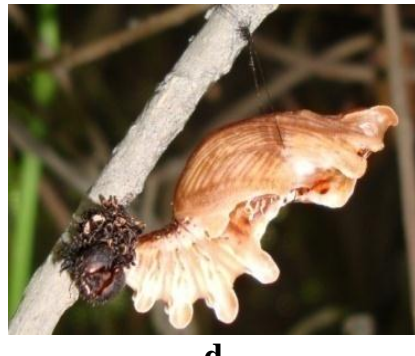

d

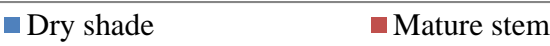

Dry shade

- Mature stem

$\square$ Neighbouring plant

Others

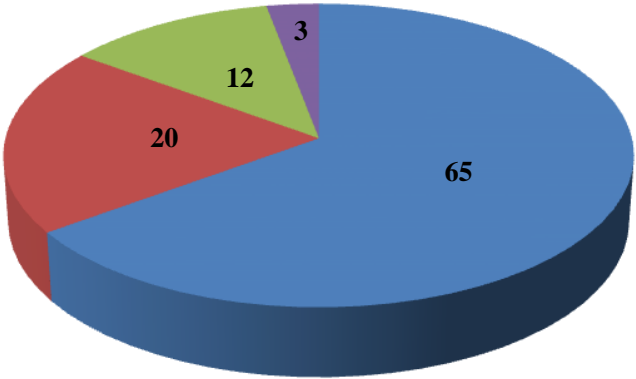

\section{Percentage of pupae $(n=145)$}

Fig. 7. Different changing states of $P$. aristolochiae while pupating on the substrates in colonizing places (a-d); a. Larva preparing for undergoing pupation, b. Second state of pupation: attaching itself with a substratum, c. Newly formed pupa showing the final pupal stage, d. Pupa in its tranquility (after 24 hours by completing pupation- strongly hanging with the substratum) and e. Percentage of P. aristolochiae pupation on different substrates (n represents the number of pupae).

\section{Egg mortality}

There were 56 P. aristolochiae eggs observed in the hedges 1 and 2 of A. indica in Zoological Garden, Curzon Hall Campus, University of Dhaka. Of which 49 eggs were hatched and seven eggs were destroyed due to predators, fungal infection, egg-laying mal-deposition, mechanical abrasion and environmental hazards, such as storm, wind-blow, heat-rise, etc. (Fig. 8.).

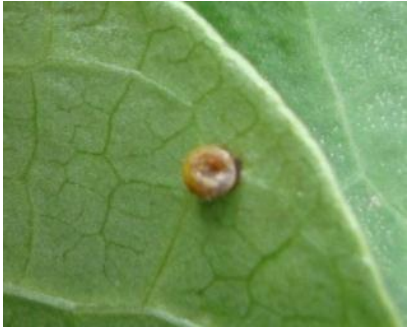

a

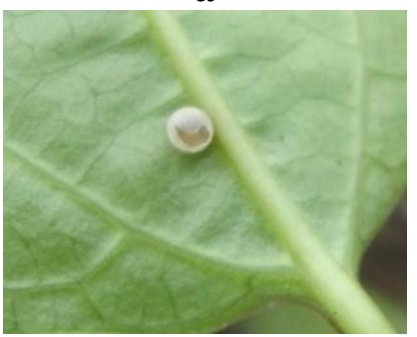

c

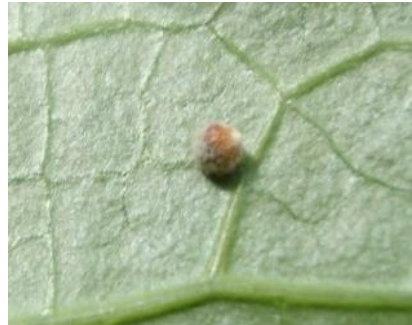

b

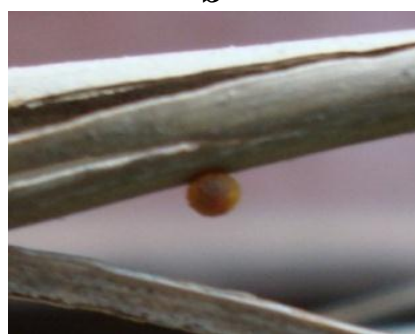

d

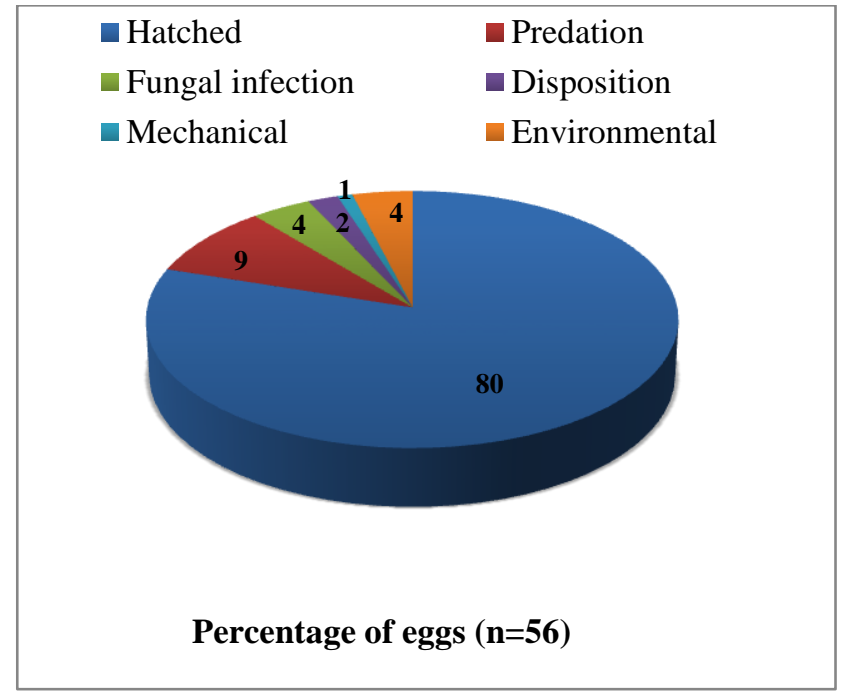

$\mathbf{e}$

Fig. 8. Some unhatched eggs of $P$. aristolochiae (a- d) due to (a, b) fungal infection, (c) predator attack, (d) mal-deposition and (e) the percentage of hatched, and unhatched eggs of $P$. aristolochiae at different aspects ( $\mathrm{n}=$ the number of eggs). 


\section{Larval mortality}

One hundred and twenty eggs were hatched in the hedges 1 and 2 of A. indica in the same experimental station of the University of Dhaka. Of which 11 larvae were lost due to predator's attack, fungal infection, spider web, mechanical abrasion and environmental hazards, such as storm, wind-blow, heat-rise, etc. (Fig. 9.).

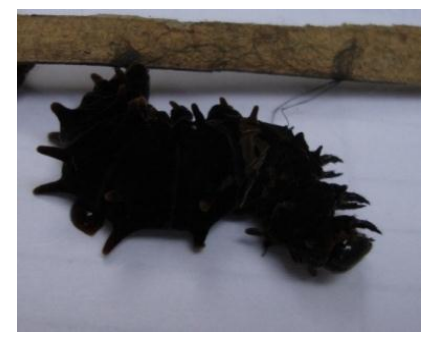

$\mathbf{a}$

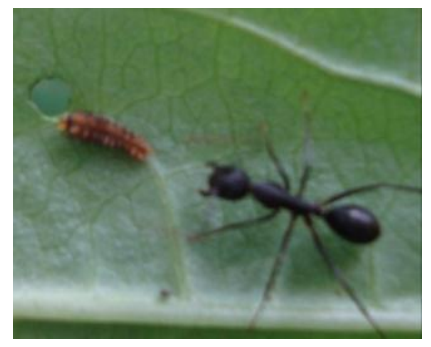

c

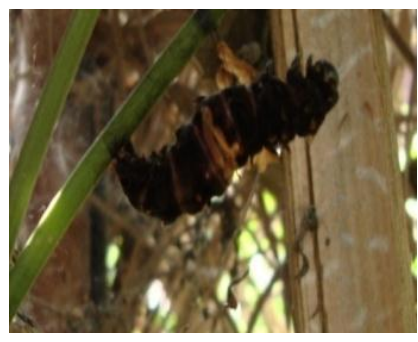

b

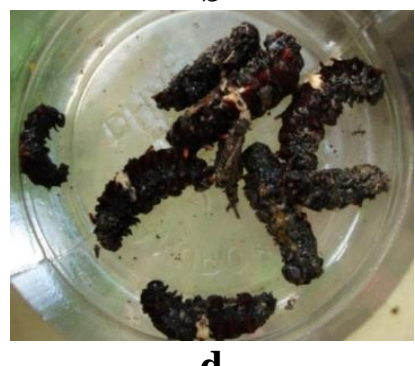

d

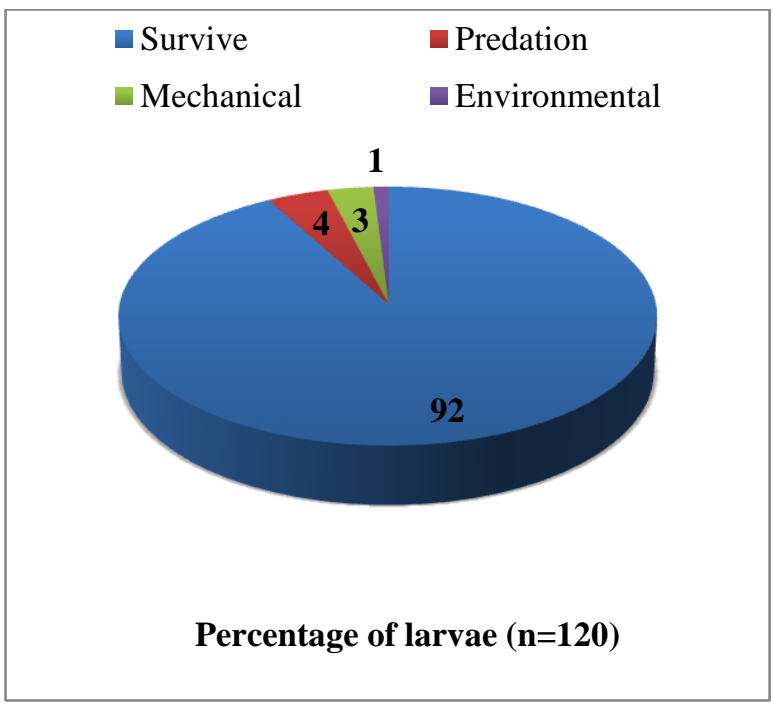

e

Fig. 9. Various causes of $P$. aristolochiae larval death (a-d); a. mechanical cause, b. biological invention, c. predator's attack, d. environment disaster, and e. the percentage of $P$. aristolochiae larval survivability and mortality with causing agents relationship ( $\mathrm{n}=$ the number of larvae).

\section{Pupal diapause}

Diapause is the delay in development in response to regularly and recurring periods of adverse environmental condition. It is a mechanism used to survive predictable, unfavourable environmental conditions, such as temperature extremes, drought or reduced food availability. The pupa of $P$. aristolochiae undergoes pupation in winter for about 3 months from December to February (Fig. 10a).

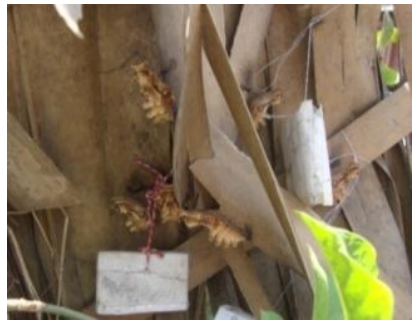

$\mathbf{a}$

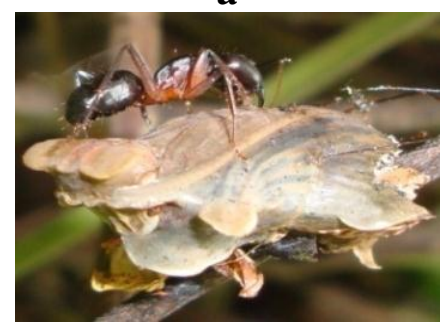

c

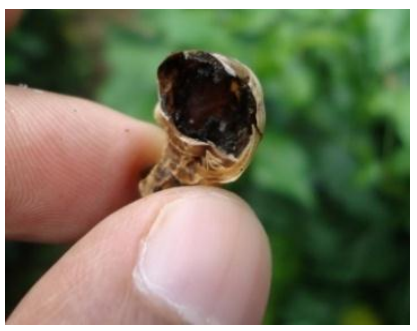

$\mathbf{b}$

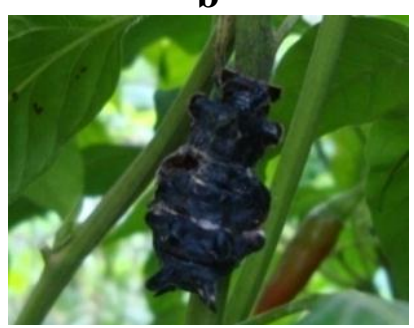

d

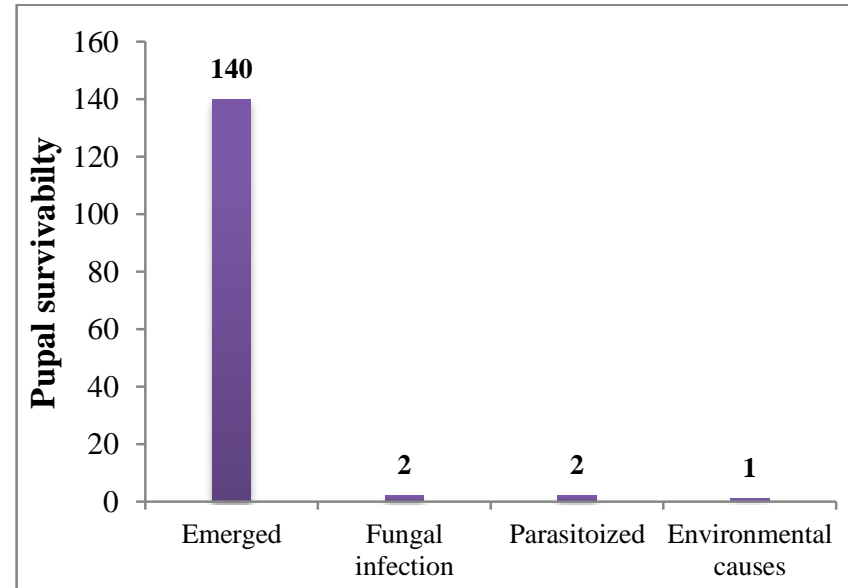

Pupal death causing agents $(\mathrm{N}=145)$

Fig. 10. a. Pupal diapauses of $P$. aristolochiae; Causes of pupal mortality: b. and c. predation, d. parasitism; e. Pupal survivability and mortality with causal factors ( $\mathrm{n}=$ the number of pupae). 


\section{Pupal mortality}

Pupal mortality was observed and recorded throughout the study period. Pupa sometimes lost due to the attack of predators, fungal infection, parasitism and environmental causes, such as storms (Fig. 10. b-d). The pupal survivability and death causing factors of $P$. aristolochiae was plotted in Fig. 10e. But the mortality rate was very low (5 out of 145 pupae).

This study records that butterfly colonization is a natural process of initiation and the process for maintenance of species richness and species assemblage in an ecosystem. This natural process in an open place can be modulated by establishing and by ensuring availability of all required necessaries and accessories for butterfly-plant interactions, which are host plants, nectar plants, shelter plants, pupating supports, and all together, abiotic supports. The colonization is also required by a balance of maintaining "general equilibrium position" theory for butterfly -plant relationships and prey predator relationships. The maintenance of plant means plantation, replacement and proper take-care of natural vegetation, cultivated host-plant, nectar plant and shade plant in the garden and cultivated forest. We should have to know about their life cycle of host plants and their diseases, in respect to their environment.

\section{REFERENCES}

Aich, U., S. Chowdhury, S. Akand, S. Rahman, K. Chowdhury, Z. Sultan and M. A. Bashar. 2016. Synchronization of coincidences between the life stages of Pachliopta aristolochiae in relation to the phenology of its host plant Aristolochia indica. J. biodivers. conserv. bioresour. manag. 2(2): $65-72$.

Alam, M. M., M. A. Bashar and H. R. Khan. 2014. Biology of common rose butterfly, Pachliopta aristolochiae Fabricius (Lepidoptera: Papilionidae) on the host plant, Aristolochia indica L. (Aristolochiaceae). Dhaka Univ. J. Biol. Sci. 23(2): 109-117.

Aravind, N. A. 2005. Ficus pumila L: A new host plant of Common Crow (Euploea core, Cramer, Lepidoptera, Nymphalidae). J. Bombay Nat. Hist. Soc. 102(1): 129.

Barua, K. K. and J. Slowik. 2007. Study on the biology and consumption potential of Common Rose Pachliopta aristolochiae aristolochiae Fabricius (Lepidoptera: Papilionidae) on Aristolochia tagala. Polish J. Entomol. 6(4): 341-352.

Bashar, M. A. 2015. Butterflies of Bangladesh: A broad approach for nature lovers (EBBL Red-List and butterfly activities). Vol. 2. 1st ed. BCTF Publications. 177 pp.

Bashar, M. A. 2014. Butterflies of Bangladesh: A broad approach for nature lovers. Vol. 1. 1st ed. BCTF Publications. 514 pp.

Bergman, M., K. Gotthard, D. Berger, M. Olofsson, D. J. Kemp and C. Wiklund. 2007. Mating success of resident versus non-resident males in a territorial butterfly. Proceedings of the Royal Society of London B: Biol. Sci. 274(1618): 1659-1665.

Che, C. T., M. S. Ahmed, S. S. Kang, D. P. Waller, A. S. Bingel, A. Martin and D. D. Soejarto. 1984. Studies on Aristolochia III. Isolation and biological evaluation of constituents of Aristolochia indica roots for fertility-regulating activity. J. Nat. Prod. 47(2): 331-341.

Chen, C.Y., F. R. Chang, Y. C. Shih, T. J. Hsieh, Y. C. Chia, H. Y. Tseng, H. C. Chen, S. J. Chen, M. C. Hsu and Y. C. Wu. 2000. Cytotoxic Constituents of Polyalthia longifolia var. pendula. J. Nat. Prod. 63(11): 1475-1478.

Gay, T., I. Kehimkar and J. C. Punetha. 1992. Common Butterflies of India. WWF-India and Oxford University Press, Mumbai, India. 66 pp. 
Haribal, M. 1992. Butterflies of Sikkim Himalaya and their Natural History. Sikkim Nature Conservation Foundation (SNCF), Sikkim, India. 65 pp.

Hern, A., G. Edwards-Jones and R. G. Mckinlay. 1996. A review of the pre-oviposition behaviour of small cabbage white butterfly, Pieris rapae (lepidoptera: Pieridae). Ann. Appl. Biol. 128(2): 349371.

Ilse, D. 1956. Behaviour of butterflies before oviposition. J. Bombay Nat. Hist. Soc. 53(3): 486-488.

Kunte, K. 2006. Additions to known larval host plants of Indian butterflies. J. Bombay Nat. Hist. Soc. 103(1): 119-120.

Lederhouse, R. C., S. G. Codella, D. W. Grossmueller and A. D. Maccarone. 1992. Host plant-based territoriality in the white peacock butterfly, Anartia jatrophae (Lepidoptera: Nymphalidae). J. Insect Behav. 5(6): 721-728.

Mamun, M., M. Bashar and H. R. Khan. 2008. Phenology and Abundance of Nymphalid Butterflies of Some Hilly Forests of Chittagong and Cox's Bazar, Bangladesh. Bangladesh J. Zool. 36(1): 11-18.

Obara, Y., H. Koshitaka and K. Arikawa. 2008. Better mate in the shade: enhancement of male mating behaviour in the cabbage butterfly, Pieris paecrucivora, in a UV-rich environment. J. Exp. Biol. 211(23): 3698-3702.

Pola, M. and M. Garcia-Paris. 2005. Marine puddling in Papiliopolytes (Lepidoptera: Papilionidae). Florida Entomologist. 88(2): 211-213.

Scott, J. A. 1974. Mate-locating behaviour of butterflies. Am. Midl. Nat. 91: 103-117

Ramana, S. V., J. B. Atluri and C. S. Reddi. 2013. Autecology of the endemic Crimson rose butterfly Pachliopta hector (Lepidoptera: Rhopalocera: Papilionidae). J. Indian Inst. Sci. 84(1): 21-29.

Wiklund, C. and C. Ahrberg. 1978. Host plants, nectar source plants, and habitat selection of males and females of Anthocharis cardamines (Lepidoptera). Oikos. 31(2): 169-183.

Wynter-Blyth, M. A. 1957. Butterflies of the Indian Region. Bombay Natural History Society, Bombay, India. $523 \mathrm{pp}$.

Young, J., S. M. Walker, R. J. Bomphrey, G. K. Taylor and A. L. Thomas. 2009. Details of insect wing design and deformation enhance aerodynamic function and flight efficiency. Sci. 325(5947): 15491552. 